\section{Acknowledgments}

We wish to thank Dr C. A. Young, Dr J. W. Litchfield and Dr R. D. Green for permission to describe these cases, and we wish to thank Professor W. S. Peart for his encouragement.

\section{References}

Byrom, F.B. (1954) The pathogenesis of hypertensive encephalopathy and its relation to the malignant phase of hypertension. Lancet, ii, 201.
FAZEKAS, J.F. (1966) Cerebrovascular consequences of hypertension-therapeutic complications. American Journal of Cardiology, 17, 608.

Finnerty, F.A., Witkin, L., Fazekas, J.F., Langbart, M. \& YounG, W.K. (1954) Cerebral hemodynamics during cerebral ischaemia induced by acute hypotension. Journal of clinical Investigation, 33, 1227.

StrandgaArd, S., Olesen, J., SkinhoJ, E. \& Lassen, N.A. (1973) Autoregulation of brain circulation in severe arterial hypertension. British Medical Journal, 1, 507.

\title{
Carbon monoxide poisoning: recovery associated with a transient dyskinetic syndrome
}

\author{
J. A. Sills \\ M.R.C.P., D.C.H.
}

\author{
ELENA VIVORI \\ F.F.A., R.C.S.
}

\section{ROSENBLOOM \\ M.R.C.P., D.C.H.}

\section{Royal Liverpool Children's Hospital, Liverpool L7 7DG}

\begin{abstract}
Although exposure to fire on domestic premises is increasingly hazardous because of the fumes produced by burning synthetic substances used in furnishings and other materials, one of the principal dangers to individuals trapped by fire continues to be poisoning by carbon monoxide. This case report illustrates the potentially severe nature of this variety of asphyxia. An account is given of the measures used in resuscitation and of the evolution of the patient's clinical condition.
\end{abstract}

\section{Case report}

The patient, a boy aged 8 years, was trapped by smoke in a house fire and subsequently rescued by firemen wearing breathing apparatus. His younger brother aged 6 years was similarly trapped and rescued but was adversely affected only to the extent of suffering fairly marked inspiratory stridor. The older boy was more seriously affected and in spite of attempted resuscitation had no spontaneous respiration on arrival at the casualty department of the Royal Liverpool Children's Hospital.

Resuscitative measures thereafter included immediate intubation and ventilation with $100 \%$ oxygen, correction of acidosis, intravenous hydrocortisone and bronchial lavage with normal saline. Shortly after admission a brief episode of decerebrate rigidity occurred and $50 \mathrm{ml}$ of $10 \%$ mannitol was given intravenously in an attempt to reverse any cerebral oedema. Two hours after admission the child's carboxyhaemoglobin level was greater than $80 \%$ and by extrapolation it was assumed to have been considerably higher at the time of admission. At this stage $200 \mathrm{ml}$ of blood was transfused in order to increase blood oxygen carrying capacity. Curarization and mechanical ventilation with $100 \%$ oxygen (in order to decrease the respiratory efforts and the oxygen needs of the patient) were continued. Carboxyhaemoglobin level $9 \mathrm{hr}$ after admission was $10 \%$ and the $100 \%$ oxygen used up to then was reduced to $40 \%$ oxygen in air.

On the following day the child, in the twilight periods between sedation and curarization, was able to obey simple commands. Extubation was possible after $72 \mathrm{hr}$ although sedation had to be continued for a further $48 \mathrm{hr}$ as he became stridulous when agitated. Seven days after admission cognitive function appeared to have fully recovered, but abnormal motor function with dysarthria, athetosis predominantly of the face and upper limbs, and a spastic diplegia predominantly affecting the lower limbs was present. After $24 \mathrm{hr}$ of these distressing symptoms dexamethasone therapy was instituted, and coincidentally the dyskinesia began slowly to resolve. 
Two weeks later, i.e. 22 days after admission, the child was able to walk, run and kick a ball, although he could not hop and his handwriting was still laboured. Formal neurological examination showed a persisting mild spastic diplegia and minimal dyskinesia of his tongue and upper limbs. Further followup and a school report have confirmed that the child hitherto has only mild neurological sequelae.

\section{Comment}

Anoxia after involvement in a house fire is mainly produced by carbon monoxide poisoning. The three-hundredfold affinity of haemoglobin for carbon monoxide compared to oxygen (Haldane, 1931) can produce $50 \%$ saturation in $15 \mathrm{~min}$ when the air concentration of carbon monoxide is only $1 \%$ (Haldane, 1930), and higher concentrations produce greater saturations even more quickly. A second contributing cause of anoxia is laryngeal and epiglottic oedema produced as a direct effect of exposure to smoke. The resuscitative measures in this patient were intended to reverse both these causes of anoxia, while at the same time producing maximal cerebral re-oxygenation. Artificial ventilation with $100 \%$ oxygen was probably the most useful single helpful measure employed, although hyperbaric oxygen, had it been available, may have been of even greater therapeutic value.

Although lifesaving, resuscitation carries its own risk of producing an individual with severe residual problems. Brain damage is a recognized consequence of the anoxia caused by carbon monoxide poisoning, and in particular the basal ganglia are likely to be affected. This patient showed this with the development of his dyskinesia (and he still, indeed, has residual physical signs), although it is not possible to know whether the administration of dexamethasone, by reducing cerebral oedema, helped to reduce the ultimate severity of this feature here. Abbott (1972) reported the use of dexamethasone in a man with prolonged coma and decerebrate rigidity fol- lowing accidental exposure to carbon monoxide, and stated that the eventual result after a 4-hr postadmission level of carboxyhaemoglobin of $20 \%$ was almost complete recovery of neurological and intellectual function.

The delay in onset of this child's dyskinesia is noteworthy. McCall (1940) described post-anoxic encephalopathy occurring up to 15 days after an incident after there had been an initial recovery, and more recently Cree (1969) reported a similar occurrence in a boy asphyxiated after inhaling a plastic bullet. The mechanism whereby this 'lucid period' is produced is not known.

Recovery after exposure to carbon monoxide sufficient to cause a level greater than $80 \%$ has not been previously reported. Indeed, Polson and Tattersall (1969) state that a saturation of $80 \%$ carboxy haemoglobin for a brief period is likely to prove fatal, and they also reported the occurrence of convulsions with a saturation greater than $50 \%$. It is possible that the relatively good results seen in this patient reflect, in part, the efficacy of the resuscitative measures used. This in turn would suggest that the prognosis following accidental carbon monoxide poisoning in young subjects may not be as gloomy as has been stated so long as vigorous resuscitation is instituted as early as possible.

\section{References}

AввotT, D.F. (1972) Slow recovery from carbon monoxide poisoning. Postgraduate Medical Journal, 48, 639.

CreE, J.C. (1969) Transient choreo-athetosis following severe anoxia. Proceedings of the Royal Society of Medicine, 62, 323.

Haldane, J. (1930) Carbon monoxide poisoning. British Medical Journal, 2, 16.

HaldaNe, J. (1931) Carbon monoxide poisoning with special relation to its medico-legal aspects. Transactions of the Medico-legal Society (London) 24, 156.

McCall, A.J. (1940) Sequelae of carbon monoxide poisoning. Lancet, ii, 759.

Polson, C.J. \& Tattersall, R.N. (1969) Clinical Toxicology, p. 609, 2nd Edition. 